\title{
Lenguaje, cultura, acción y cambio ${ }^{1}$
}

\author{
BEATRIZ GARZA CUARÓN \\ Investigadora del Centro de Investigaciones \\ Interdisciplinarias en Ciencias y Humanidades \\ de la UNAM. Torre II de Humanidades \\ Ciudad Universitaria Tel 6230018
}

\section{RESUMEN}

Se analizan las relaciones de los signos con la realidad, la mayor o menor adecuación de las necesidades de los hablantes respecto de los signos lingüísticos que emplean. Estas relaciones del lenguaje son también con el pensamiento de una cultura, pues el sistema de signos se adapta a cualquier situación cultural. Se revisa esta relación desde Humboldt, hasta Austin, pasando por Saussure, Boas, Sapiry Whorf entre otros. La conclusión para nuestro mundo actual es que hemos de ser flexibles y adoptar los términos técnicos provenientes de otras lenguas (y consecuentemente otras culturas, otras maneras de ver y, sobre todo, de nombrar la realidad). Las innovaciones, sobre todo las tecnológicas, entran en otras culturas con su léxico correpondiente, es inútil oponerse a extranjerismos imbricados con las tecnologías que necesariamente tenemos que importar. Lo que sí tenemos que hacer es adaptar las palabras de otra lengua a la pronunciación de nuestro español.

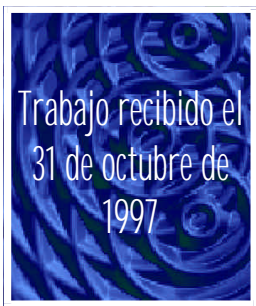

\begin{abstract}
The paper approaches the relations of signs with reality, the greater or lesser fitting of speakers' needs with respect to the linguistic signs they use. These language relations are also with the thoughts of a culture, for the sign system adapts itself to any cultural situation. The relation is reviewed from Humboldt to Austin, including, among others, Saussure, Boas, Sapir and Whorf. The conclusion for our modern world is that we must be flexible and adopt the technical terms coming from other languages (and consequently other cultures, other ways of understanding and, above all, naming reality). Innovations, mainly technological, enter into other cultures with their corresponding lexicon; it is useless to oppose these foreign words closely knit with the technologies we necessarily have to import. What we certainly have to do is to adapt those words from other languages to our Spanish pronunciation.
\end{abstract}

1 Una versión más amplia de este trabajo será publicada por el Centro de Investigaciones Interdisciplinarias en Ciencias y Humanidades de la UNAM. 
F l mensaje lingüístico implicauna determinada captación y ordenación dela reali-

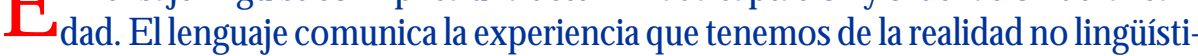
ca, en la medida en que nos es común con los demás usuarios de una lengua. Además, el lenguaje es el instrumento mediante el cual, en cierta manera, el hombre da forma a su pensamiento, a sus sentimientos, o a sus estados de ánimo, sus aspiraciones, su querer y su actuar, y por medio del cual recibe influencias del exterior; en estesentido, el lenguaje es el cimiento más firmey profundo de la sociedad humana. Es decir, el lenguaje reproduce, por medio de un sistema de signos la realidad objetiva y subjetiva de los hablantes.

Las lenguas no son un único y mismo calco de una realidad invariable. Las lenguas tampoco son nomenclaturas, listas de palabras, asociadas por convención a objetos 0 a significados que existen independientemente de la lengua. Cuando se aprende una lengua extranjera podemos constatar rápidamente que esa lengua hace distinciones de significados que no hace la otra lengua. Aprender el vocabulario de una lengua extranjera no es simplemente adquirir una nueva serie de etiquetas y relacionarlas con significados ya familiares, sino entrar en una nueva manera de observar y percibir el mundo.

La asociación que se da entre la lengua y la realidad no lingǘstica es sumamente interesante, puesto que no se produce de una manera directa e igual en todas las lenguas. Según la experiencia común a todos los miembros de una sociedad, cada lengua ordena, clasifica y analiza esta experiencia común, y la enfoca de una manera particular.

Veamos unos ejemplos de esto:

Los términos para el color usados en las distintas lenguas no se corresponden exactamente unos a otros. Evidentemente existen diferencias físicas en el espectro del color, sin embargo, las lenguas lo dividen en diferentes formas:

x en galés, gas 'Zona del azul y el verde en español'

$x$ en hindi, pita Puede traducirse en español como 'amarillo, anaranjado o café'

$x$ en ruso, glabof 'azul claro'

x en ruso, sinii 'azul oscuro'

Hay lenguas que sólo distinguen dos colores básicos que corresponden a dos mitades del espectro; otras hacen muchas más distinciones que el español. En esquimal no hay una palabra para 'nieve' sino que hay muchas designaciones para los diferentes tipos de nieve, dada la importancia que tiene este elemento en su vida cotidiana. Incluso en lenguas emparentadas entre sílos datos de la experiencia se organizan de una manera particular en cada una. 
La estructuración del vocabulario y la cultura dependen también de la situación peculiar de cada grupo social. El factor más importante para la construcción del vocabulario de una lengua es la estructura de la cultura en el seno de la cual esta lengua es el principal medio de comunicación. Es decir, los hablantes delimitan la realidad de diferentes maneras, de acuerdo con sus necesidades prácticas, e incluso hacen cambios cuando así lo requieren. Como en el caso de los esquimales con la nieve, cada colectividad exige una estructuración particular del lenguaje. Así, el árabe tiene muchas palabras para distinguir diferentes tipos de camellos. Una comunidad que vive en una región selvática necesitará un vocabulario más extenso en cuanto al reino vegetal para poder discriminar y aprovechar de manera adecuada su medio ecológico. Un pueblo de pescadores, por lo mismo, posee un léxico ictiológico muy amplio que no tiene por qué ser conocido por un habitante de zonas del altiplano. Incluso dentro de una solalengua el vocabulario de un campesino y el de un hombre dela ciudad no es el mismo, porque sus necesidades expresivas son distintas. El de la ciudad llamará a todas las coníferas, PINO, en cambio el hombre de la montaña distinguirá diferentes tipos. En español, por ejemplo, distinguimos gallo / gallina, pollo; en cambio no distinguimos ni el sexo, ni la edad del águila o de la golondrina, porque la gallina tiene una presencia indudable en nuestra vida diaria.

Por ejemplo, el niño pequeño cuando empieza a hablar llama dada todo lo que tiene cuatro patas y una cierta altura: el caballo, la vaca, el asno, el perro grande y tal vez la cabra, el elefante, lajirafa, o el camello que ve en el zoológico; o no distingue, por ejemplo, entre las distintas clases de agua como mar, río, charco, alberca, etcétera, sino que a todo le llama agua. Esto se debe exactamente al mismo proceso por el que llamamos águila o golondrina a la vez al macho, a la hembra y a su cría, es decir, nuestra práctica social no nos incita a distinguirlos, y por tanto a nombrarlos separadamente. Por estos ejemplos puede verse que, al comienzo, el niño sólo posee una clasificación general para animales o para agua, que poco a poco irá delimitando según sus necesidades, intereses y conocimientos. En un sentido estricto puede decirse que lo que no se nombra carece de existencia distintiva para el hablante. Por eso, cuando se crean nuevos inventos, se introducen junto con el vocabulario dela cultura que los creó y, en adelante toda so ciedad que accede al cambio, adopta esos nuevos puntos de vista, junto con sus estructuras lingǘsticas.

D elo anterior, se desprende queel signo lingüístico se relaciona con la realidad de una manera arbitraria. Puesto queel lenguaje es la facultad del hombre de reproducir y recrear, por medio de un sistema de signos, la realidad que percibe, y puesto que hemos visto que una misma realidad se percibe de distinta manera, es necesario entonces ver la relación de estos signos con la realidad. La caracteństica fundamental del signo es ser arbitranio, es decir, la asociación entre una palabra y su significado es siempre convencional; no hay ninguna analogía entre la forma y el sentido, entre la expresión y el contenido. La función del signo es representar algo distinto de sí mismo. En las lenguas hay ciertas formas llamadas onomatopéyicas en 


\section{Investigaaón Biblicteedógicav. 11 No. 23 julio/ diciembre de 1997}

las que sí hay analogía entre la forma del mensaje y su significado: tic-tac, glu-glu, fru-fru (tela). Aunque aún en estos casos, la forma que le da cada lengua a los sonidos en apariencia onomatopéyicos es muy distinta. Por ejemplo, en español, el gallo hace quiquiriquí [kikinikí]; en cambio en inglés hace cock-a-doodle-do [kdkadudldúj; y en francés, coquerico [kokeikó].

También existe arbitrariedad en la formación de las estructuras gramaticales. De la misma manera que en el léxico, las estructuras gramaticales se organizan de distinta forma en cada lengua. D entro de este aspecto no se puede ver tan claro el reflejo de la práctica social: ¿Por qué hay lenguas que prácticamente carecen del reflexivo? ¿Por qué es más importante en las lenguas indígenas americanas el aspecto verbal y por qué las lenguas románicas le dan tanta importanciaal tiempo? É stas son preguntas que no podemos contestamos. Tampoco podemos saber por qué son tan diferentes las siguientes estructuras sintácticas:

x español: me duele la cabeza

x francés: j’ai mal àla tête(tengo una mal en la cabeza)

‘ inglés: I havea headache(tengo un dolor de cabeza)

x ruso: umerjabdit'gdowa (en mi sufre la cabeza)

Es obvio que cada una de ellas expresa "visiones del mundo" muy diferentes, cuyo origen estructural desconocemos porque se ha olvidado en muchos casos.

¿Por qué en nidivat, una de las lenguas de la India, en la costa del Pacífico, las divisiones del día, la noche, el año, la mañana, el verano, son adverbios de tiempo, sin posibilidad de plural, de artículo ni de posesivo?

Hay lenguas en las que hay tres formas distintas que indican número, en griego, por ejemplo, hay singular, plural, dual. En cambio, en zapoteco el número se indica exclusivamente por medio de adjetivos que se agregan al sustantivo. Muchas lenguas, como el español, distinguen dos tipos de género, masculino/ femenino: perro perra, banco - banca; otras, tres, latín: femenino/ masculino/ neutro: rosa - leo -templum. Hay lenguas en las que el sustantivo se flexiona, como en latín y alemán, de ahí las declinaciones.

Puede decirse que, sea o no clara la correspondencia de las estructuras gramaticales con la práctica social, cadalengua organiza su material en los distintos niveles, según las necesidades inherentes al propio sistema lingüístico que en último término, corresponden a las necesidades de los hablantes.

Veamos ahora la relación del lenguaje con el pensamiento derivado de una cultura. El hombre con ayuda del lenguaje distribuye y organiza el mundo; del caos de las apariencias crea un sistema organizado. D ado que el hombre transmite esta organización idiomática del mundo a la generación siguiente, por el lenguaje recibe también una determinada visión de las cosas, es decir, el lenguaje, el pensamiento y la cultura están en una relación de interdependencia. 
Esto nos hace pensar quelalengua en sí es un prisma, puesto que nos acostumbra a estructurar los datos dela experiencia de cierta manera; pero, al mismo tiempo, por las infinitas combinaciones posibles en toda lengua, nos permite una total apertura mental. El sistema de signos no está ligado a ciertos estados o situaciones fijas, sino que su flexibilidad le permite adaptarse acualquier situación cultural. Es decir, dada la necesidad de expresar una situación, cada lengua llega por su propio camino a una estructuración distinta. Por esto, no podemos decir que hay lenguas primitivas y lenguas evolucionadas. Unas podrán ser más pobres léxicamente, sobre todo porque viven en una realidad más pobre, pero todas están en posibilidad de expresar toda clase de conceptos.

Entre los innovadores en percibir las lenguas como prismasa través de los cuales se vive y se contempla una realidad, está G uillermo de Humboldt, quien fue uno de los pensadores más profundos del siglo X IX en cuestiones de lingüística general. Su contribución no es tan conocida como sería posteriormente la de Ferdinand de Saussure, sin embargo, a Humboldt se le puede considerar como uno de los pocos lingüistas que dio inicio en el siglo X IX, a una nueva filosofía lingüística. G uillermo deHumboldt, como su hermano Alejandro, tuvo ocasión de viajar por muchos países y conocer varias lenguas occidentales y orientales, y también, algunas lenguas americanas. Esto le dio la oportunidad de comprender mejor cómo cadalengua enfoca su realidad de distinta manera.

En su teoría del lenguaje, Humboldt destaca el aspecto creativo de la habilidad lingüística de todo ser humano. El lenguaje, dice, debe ser identificado con la capacidad vital que tenemos todos los hablantes de produciry entender enunciados. Hace resaltar que el lenguaje tiene una habilidad creadora, a la que llama "enéggia", que contrasta con el mero producto lingüístico al que llamó "egon". Humboldt se opone a que las lenguas sean identificadas con los productos inertes analizados por los gramáticos; por eso las lenguas son acción y cambio. La capacidad del lenguaje es una propiedad esencial de la mente humana, que a través del medio ambiente, en el que crece la persona, hace surgir una lengua. En virtud de la propia naturaleza de esa capacidad mental, las lenguas son susceptibles de alterarse e ir cambiando, adaptándose a las exigencias de las circunstancias. D entro de esta concepción, se puede explicar la parte central y un tanto misteriosa del lenguaje: la posibilidad que tenemos los hablantes de hacer un uso infinito de los recursos lingüísticos.

Lo novedoso de la teoría de Humboldt consiste en que al mismo tiempo que admite que la facultad del lenguaje es universal, sigue el pensamiento de otros lingüistas, como Herder, que consideran las características individuales de cada lengua como manifestaciones de las peculiaridades de cada grupo social. Las bases articulatorias para hablar son comunes a todos los hombres, pero son únicamente una materia pasiva para la estructura o la organización formal del lenguaje (innere Spradform. Esta "forma interior del lenguaje" corresponde ala estructura semántica y gramatical de una lengua y responde alos elementos, esquemas y reglas a que se so- 
mete la materia prima del habla. La estructura semántico-gramatical es común a todos los individuos, puesto que es una especie de equipo intelectual inherente al hombre, pero por otra parte, la especificidad de cada lengua sirve para identificarla formalmente y distinguirla de los demás idiomas. Este principio de organización de cada lengua domina las estructuras silábicas, la gramática y el léxico. Q ueda a los lingüistas y a los creadores literarios explorar los límites máximos o el campo de potencialidades de la forma interior del lenguaje dentro de cada lengua. Humboldt lleva adelante el paralelo entre el desarrollo del pensamiento y el lenguaje, y concluye que la cultura, el modo de pensary el modo de hablar de un pueblo están íntimamente ligados: "la lengua de un pueblo es su espíritu y su espíritu es su lengua".

Para Humboldt el pensamiento y la percepción se definen y se vuelven comunicables por medio del lenguaje: el pensamiento y el lenguaje son interdependientes e inseparables. Las palabras no son rótulos o nombres individuales, sino que al contrario, sirven para denotar una cosay colocarlaal mismo tiempo en una determinada categoría del pensamiento. Las palabras de una lengua constituyen un sistema, de modo que cualquiera de ellas, cuando es enunciada, tiene siempre detrás de sí, toda una estructura semánticay gramatical de la que es parteintegrante. Esto quiere decir, que de ninguna manera es cierto que las diferencias entre las lenguas estén sólo en el aspecto fónico; sino que difieren también en cuanto a la interpretación y la comprensión que tienen los sujetos hablantes del mundo en queviven. Podemos ver con relativa facilidad que este mundo de los hablantes, como el mundo propio de cada uno de nosotros, hasta cierto punto, cambia constantemente con las innovaciones de todaíndole que se van produciendo. Y así también, tiene que cambiar y evolucionar la lengua.

La influencia de la manera de pensar de Humboldt se hizo sentir muy pronto. El fundador dela psicología experimental, W. Wundt, en sus estudios de psicología lingüística y psicología nacional, se reconoce influido por las teorías de Humboldt. Su influencia también se dejó sentir en la escuela estética e idealista a través de las ideas sobre individualidad, creatividad y potencialidades artísticas de cada lengua. Más recientemente, ya en el siglo XX, tanto en Europa como en América, surgen varias corrientes neohumboldtianas. En los Estados Unidos, sobre todo en el campo de los estudios de las lenguas indígenas, se puede trazar una línea que comienza en Humboldt, pasa a Franz Boas, sigue con Edward Sapir, y desemboca en Benjamin Lee Whorf. En las lenguas indoamericanas se aprecian muy claramente los cambios radicales que se introducen al ser influidas por culturas distintas.

El lingüista que indudablemente siguió, en algún aspecto, la teoría de Humboldt, en cuanto a la relación lenguaje-pensamiento, fue Ferdinand de Saussure, quien puede ser considerado el fundador delalingüística moderna. Sus cursos fueron recogidos y ordenados a partir de las notas de sus discípulos después de su muerte y publicados en 1915, como el bien conocido Carsdelinguistiquegénérale A los puntos de vista de Ferdinand de Saussure también se les ha considerado el pro- 
ducto más profundo y a la vez más clarificador del positivismo derivado del siglo XIX. Sin embargo, su doctrina es algo más que el resumen de una escuela científica superada. A partir de su riguroso y sistemático deslindamiento devarias parejas de conceptos, Saussure clarificó el objeto de estudio del lenguaje y dio pie al desarrollo de la lingüística moderna. Estas parejas de conceptos bien conocidas son: lengua y habla, sincronía y diacronía. Pero, también, su concepto de sistema basado en la noción complementaria de valor es uno de los que más han contribuido a entender las lenguas como sistemas de pensamiento y de acción, y no sólo como medios de comunicación. Su concepción estructuralista de que las lenguas son sistemas en que todos los términos son solidarios unos con otros, permite que las entidades de los sistemas lingüísticos funcionen. Por ejemplo, si tibiotiene un significado es porque no es ni fŕoni caliente sino que tiene una situación intermedia que le da su valor gracias a la existencia de los otros términos. Lo mismo los términos que son declinables en algunas lenguas, sólo tienen valor en relación con los demás. El valor consiste en la solidaridad e interdependencia de una significación con las otras significaciones; el valor emana del sistema e implica en cada elemento la presencia concreta del sistema en su conjunto. La significación, como bien dice Saussure, no se debe a la relación entre un nombre y un referente aislado. En este sentido, es la primeravez que se enfoca el problema de significar en el terreno concreto de los sistemas de las lenguas y no en el abstracto de la lógica que aísla todo significado del sistema.

Este concepto de las relaciones entre cultura, lengua y pensamiento es mucho más profundo que el asociacionismo que se había dado entre los lingüistas positivistas, los llamados neogramáticos. La posición de Saussure está en la misma dirección que la forma interior del lenguaje de Humboldt, que ya hemos visto. ${ }^{2}$

O tro lingüista que contribuyó a demostrar concluyentementeel valor de las aproximaciones estructurales entre cultura, pensamiento y lenguaje fue Edward Sapir, que demostró que los vocabularios en lenguas distintas, en muchos campos, no son iguales, no son isomórficos: que en una lengua hay distinciones semánticas que no se encuentran en otray, además, que determinados campos pueden categorizarse de una manera totalmente distinta en lenguas diferentes. El ejemplo que suelen dar los lingüistas, al hablar de esta relatividad semántica, es el de los términos de color que ya vimos antes. Sapir, con mucha sabiduría afirmó: "los mundos en que viven las distintas sociedades son mundos distintos y no el mismo mundo con distintas etiquetas pegadas" (como es el prisma de Humboldt).

Para vislumbrar mejor la relación cultura, pensamiento y lenguaje, también debemos entender que los sistemas léxicos de cada lengua no presuponen necesariamente una sustancia subyacente. Por ejemplo, para nuestros propósitos de

2 También está relacionada con la "actitud categorial" o clasificatoria de Bergson y con la filosofía de las formas simbólicas de E. Cassirer. 
argumentación, las palabras honestidad, sinceridad, veradidad, lealtad, fiddidad etcétera, entran en un sistema léxico con el concepto virtud La estructura de este sistema de conceptos sólo se puede describir con base en las relaciones de sentido que mantienen entre sí sus miembros. En síntesis, las correlaciones en el mundo semántico de las lenguas no sólo pueden ser descritas con base en la existencia de un referente, sino también por medio de las correlaciones que van marcando entre sí todos los miembros de un mismo campo semántico.

Uno de los primeros lingüistas que habla del lenguaje como acción, es Leonard Bloomfield. Paraél, que se basa en situaciones conductistas tipo estímulo-respuesta, la lengua es lo que permite que una persona pueda tener una reacción, mientras otra persona tiene el estímulo correspondiente. Su ejemplo es el siguiente: van por un camino Jack y Jill. D e pronto, Jill siente hambre y ve un árbol de manzanas, y en vez de ir a coger una manzana para satisfacer su hambre traslada su estímulo a Jack, a quien le pide que le traiga una manzana. D e esta manera, el estímulo fue recibido por Jill y la respuesta satisfecha por Jack. Así, dice Bloomfield, "la división del trabajo y con ella la labor entera de la sociedad humana se debe a la lengua". ${ }^{3}$

La lengua para Bloomfield también es el soporte del pensamiento y la cultura, y depende de la facultad humana que tiene toda comunidad social para construir una lengua. Las acciones humanas, entre ellas las lingüísticas, son parte de secuencias complicadas de causa y efecto en nuestro sistema nervioso. Para que esto se lleve a efecto es necesaria, además de la facultad física, el entrenamiento y el hábito. El niño, por ejemplo, al aprender a hablar, primero emite sonidos; segundo, imita sonidos. En tercer lugar une el estímulo al sonido en presencia (por ejemplo: a su madre le dice, ma). En cuarto lugar, aprende lo que es el habla abstracta, es decir, nombrala cosa inabsentia. Por último, aprende a hacerlo bien para que le entiendan y adquiere los hábitos necesarios para actuar conforme a las normas convencionales.

Aunque ya varios lingüistas y filósofos habían visto el lenguaje como un medio de producir acciones, en los años sesenta se publica una obra muy importante del filósofo inglésJohn L. Austin, su libro HoutodbThingswithWords A hí Austin acepta que durante mucho tiempo los filósofos dieron como un presupuesto que el papel de un enunciado lingüístico sólo podía describir algún estado de cosas o enunciar o constatar algún hecho, con verdad o falsedad. A éstos A ustin los llamó enumiadosconstativos

Sin embargo, el principio que llevó a A ustin a revolucionar lafilosofía del lenguaje fue el preguntarse por otro tipo de oraciones. Él mismo nos explica: "Es cierto que los gramáticos han señalado siempre que no todas las «oraciones» son (usadas para formular) enunciados: tradicionalmente, junto a los enunciados (de los gramáticos) hay también preguntas y exclamaciones, y oraciones que expresan órdenes o deseos o permisiones." 4 Austin observa, también, que no todos los

3 Leonard Blommfield. Lengaje p. 27.

4 John L. A ustin, Cómohacer cosas con palabras Palabrasyacciones Trad. de G enaro R. Carrió y Eduardo A. Rabossi. p. 41. 
enunciados que parecen descriptivos sirven para indicar alguna característica de la realidad, sino queindican simplemente, las circunstancias en que se formula el enunciado o las restricciones a que está sometido o la manera como debe ser tomado. E sto quiere decir que no todos los enunciados, verdaderos o falsos, son descripciones. Aparte de éstos, Austin tomó en cuenta expresiones que aparentemente podrían ser enunciados en un sentido lógico, puesto que tienen verbos en primera persona del singular del presente de indicativo en voz activa, pero que los filósofos no tomarían normalmente como enunciados, puesto que no podría probarse que son verdaderos o falsos. Sus características son, que estas expresiones, primero "no describen o registran naday no son verdaderas o falsas, y segundo, que el acto de expresar la oración consiste en realizar una acción o parte de ella, acción que a su vez no sería normalmente descrita como consistente en decir algo." 5

Los ejemplos que Austin da son las siguientes acciones lingüísticas:

1.- "Sí, juro (desempeñar el cargo con lealtad, honradez, etcétera”), expresado en el curso de la ceremonia de asunción de un cargo.

2.- "Bautizo este barco QueenElizabeth", expresado al romper la botella de champaña contra la proa.

3.- "Lego mi reloj a mi hermano", como cláusula de un testamento.

4.- "Te apuesto cien pesos a que mañana va a llover".

Todos estos ejemplos indican que emitir esas expresiones es realizar determinadas acciones y que éstas no se conciben normalmente como el mero decir algo, sino que exigen ejecutar algo, por lo tanto, los denomina adtos gjeativos

En síntesis, lo que interesó a Austin, fue la diferencia entre decir algo y hacer algo con la lengua. D e estos puntos de vista se dedujo que producir un enunciado puede ser entablar un cierto tipo de interacción social, por lo que el término que surgió para denominar este tipo de interacción social fue "acto de habla" (speechad). Sin embargo, aunque no se explicita, dentro de la teoría de Austin pueden entrar actos no verbales o no lingǘsticos que satisfacen la definición de Austin para actos de habla. Por ejemplo, entre dos personas el darse un apretón de manos puede cerrar un trato comercial y, por lo tanto, hacer un cambio en sus relaciones mutuas.

Austin, posteriormente, presentó una distinción tripartita, que se conservó a través de su continuador John Searley en adelante, entre tres tipos de actos de habla:

1.- Adoloativoes un acto de decir, es la producción de un enunciado significativo "en el sentido filosófico de la palabra, es decir, con un cierto sentido y una cierta referencia,"6 y que puede ser verdadero o falso.

2.- Adoilcativoes un acto realizado al deciry ala vez al hacer algo: por ejemplo, hacer una aseveración o una promesa, emitir una orden o un ruego, formular una pregunta, bautizar un barco, etcétera.

5 Ibidem pp. 45-46.

6 Ibidem p. 94. 
3.- Adopedoativoes un acto realizado por medio del decir algo: hacer que alguien crea que algo es así, persuadir a alguien de que haga algo, mover a otro a la ira, consolar a alguien en su aflicción, etcétera.

Conviene distinguir muy claramente lo que es la fuerza ilocutiva de un enunciado de su efecto perlocutivo. Esto quiere decir que ambos son componentes independientes del acto de enunciación: la fuerza ilocutiva se reduce a la condición de promesa, amenaza, ruego, declaración, exhortación, que emite el hablante; en cambio, el efecto perlocutivo de un enunciado se refiere a que se está actuando directamente sobre las creencias, actitudes o conducta del destinatario y, en muchos casos, se está esperando alguna acción consecuente de parte del receptor. Por ejemplo, si Juan le dice a Pedro jierala pueta! se puede conseguir que Pedro obedezca la orden y cierre la puerta, al obedecer y cerrar la puerta tenemos el efecto perlocutivo de una acción y no se debe confundir con su fuerza ilocutiva, que es haber dado la orden.

Todo acto ilocutivo debe satisfacer determinadas condiciones de cumplimiento. La primera es que la persona que ejecuta el acto debe tener derecho o autoridad para realizarlo. Por ejemplo, una persona no puede bautizar un barco diciendo simplemente llamba stebarcoLibetadal margen de la situación de enunciación. La persona que realiza el acto del bautizo debe estar autorizada para hacerlo y producir el enunciado en el curso de una ceremonia bien instituida. Si no se cumplen estas condiciones preparatorias, el acto resultará nulo y vacío. La segunda condición es la de sinceridad. Por ejemplo, si alguien bajo juramento en un juzgado comete perjurio al decir una mentira o algo que no cree, el acto ilocutivo quedará anulado. Lo mismo sucede cuando se llega a confundir la cortesía con la sinceridad. Cuando por simple cortesía alguien le dice al otro sin creerlo iqué inteligente es usted! el acto ilocutivo no tiene efecto. En tercer lugar, la última condición es la de ser esencial. La persona que ejecuta el acto se compromete por la fuerza ilocutiva de su enunciado a mantener ciertas creencias o intenciones; y si produce un enunciado incoherente con esas creencias, o se comporta de un modo incompatible con las intenciones que había mostrado, puede ser juzgado culpable de incumplimiento de palabra 0 , simplemente, traidor.

En resumen, de la distinción de Austin entre enunciados constativosy enunciados geativos nos queda lo siguiente: los enunciados constativos son aseveraciones cuya función consiste en describir algún evento, proceso y circunstancia y tienen la propiedad de ser verdaderos o falsos; los enunciados geutivos, por el contrario, carecen de valor veritativo y se emplean para hacer algo. Así, Austin desafió la concepción restringida de significado que sostenían los lógicos positivistas, según los cuales, los enunciados totalmente significativos sólo eran las aseveraciones empíricamente verificables; el resto de los enunciados se clasificaban como emotivos. Ésta fue la causa de que antes de Austin y Searle, el término emdivose usara además de en filosofía, 
también en la crítica literaria de manera muy laxa, para referirse no simplementealos enunciados metafísicos, sino a todo discurso que no pudiera ser verificable.

Podemos ver ahora que, lo que Austin ofrece es una teoría del significado de los enunciados en el marco de una teoría general de la actividad social. En realidad, su teoría del significado, como la de Wittgenstein, y como la posterior de John Searle, puede describirse como una teoría contextual del significado, lo cual tiene la ventaja de crear un puente entre el abismo que existió durante mucho tiempo en los puntos de vista filosóficos, sociológicos y antropológicos sobre la semántica. También hay que destacar que la teoría de Austin sobre los actos de habla conserva muchos aspectos válidos y provechosos de la semántica conductista. No es, de ninguna manera, una teoría conductista en sentido estricto, pero tampoco es incompatible con una versión ampliada del conductismo.

Es necesario tener en cuenta que muchos de los actos de habla que hemos mencionado son de carácter universal, en especial, hacer declaraciones, formular preguntas, ordenar, pedir, son universales, en el sentido en que son actos que se realizan en todas las sociedades humanas. En este sentido, no se puede hablar de convenciones. Sin embargo, hay ciertos actos de habla que dependen de conceptos legales 0 morales institucionalizados, distintos en cada sociedad. El ejemplo de Austin de bautizar un barco es uno de ellos; otro acto convencional es prestarjuramento en un juzgado, o bautizar a un niño en la fe cristiana, o conferir un título universitario.

Por otra parte, hay que distinguir ${ }^{7}$ entre decir algo en el sentido pleno de la palabray articular o pronunciar sin comprometerse. Ningún acto ilocutivo se realiza si el hablante no comprende lo que está diciendo o si no quiere realizar efectivamente tal acto. Pero esto no quiere decir que su audiencia no crea que sí se está realizando un acto ilocutivo. Por ejemplo, si se nos juzga culpables de haber roto una promesa, no se va a tomar en cuenta si al prometer nosotros internamente no queríamos cumplir con tal promesa, sino que seremos culpables de incumplimiento.

Pasando ahora a lo que es el cambio en las lenguas, además de todo lo que hemos mencionado en relación con los cambios constantes que tienen lugar en las lenguas, debemos recapacitar sobre uno de los cambios culturales y, por lo tanto, lingüísticos más fuertes que se han producido en los últimos años. Esto es, el avance de la informática y su llegada a cada escritorio personal de todo investigador. En la actualidad nos es ya casi imposible trabajar sin la valiosa ayuda de una computadara (término correspondiente al continente americano) o de un adknador (galicismo que entró ya al español de la península Ibérica). Resultanatural que al mismo tiempo que utilizamos los instrumentos informáticos desarrollados en su mayoría en los Estados Unidos, usemos también el vocabulario que nos llega junto con el instrumento. Por ejemplo, es ahora muy frecuente decir acceder(derivado de toaccess); enviamos un email, en vez de un correo electrónico; scaneamosun texto o una fotografía (derivado de scanner), y

7 Véase Z. Vendler, Res cogtans Ithaca, N.Y.-London, 1972, p. 6 y ss. 
hasta decimos, a veces, tipear (de totype. Pero contrariamente a lo que hubieran dicho los académicos y los profesores puristas de la primera mitad del siglo XX, hoy nadie pretende ya cambiar tecnicismos co mo modem como fax y faxer, como colrom, o compactdisk, por palabras aparentemente más castizas. La innovación que provoca los cambios entra en las culturas con su léxico correspondiente. Así ha sido alo largo de la historia; no es algo privativo de este fin de siglo, sino que es un fenómeno natural de toda innovación y de todo cambio. Por ejemplo, cuando el latín era la lengua llamada de cultura, todos los demás idiomas usaban los términos técnicos latinos; de esa manera, el inglés, por ejemplo, estálleno de latinismos; y en una época sucedió lo mismo entre el griego y el latín: los romanos adoptaron la cultura griega más desarrollada que la propia, junto con su vocabulario. Esto nos deja ver que debemos ser flexibles y adoptar el término técnico que más nos convenga sin temer que se trate de un extranjerismo. Lo único que tenemos que hacer es adaptar las palabras de otra lengua a la pronunciación de nuestro español.

En resumen, para concluir, podemos decir sobre nuestra cuarteta o quinteta, lenguaje, cultura, pensamiento, acción y cambio, que la capacidad lingüística del ser humano es la que nos permite no sólo expresar nuestros pensamientos, sino también nos lleva a actuar en sociedad. Sin embargo, debemos hacer algunas salvedades desde la visión a la que actualmente han llegado las ciencias del lenguaje. El pensamiento no es simplemente una masa amorfa como pensaba Saussure, sino que, a partir sobre todo de las contribuciones de Jean Piaget y sus seguidores, sabemos que el pensamiento es una capacidad inherenteal hombre que, aunque puede estar modificada por el idioma de cada comunidad lingüística, tiene también su desarrollo propio que incluye el lenguaje y muchas otras capacidades.

En cuanto al relativismo y al determinismo lingüístico de Sapir y de Whorf, hoy ya no se puede decir que cada grupo social esté totalmente predeterminado por su lengua, sino que un ejemplo muy claro lo dan las lenguas que exportan los imperios: es perfectamente posible que pueblos tan distintos como los hispanoamericanos 0 los australianos adopten lenguas como el español o como el inglés como propias. Con esto no queremos restarle, de ninguna manera, importancia al hecho de que cada pueblo tiene el derecho de conservar su propia lengua, puesto que de ella depende en gran medida, su visión del mundo, pero no podemos cegarnos ante las evidencias de la historia: un grupo social homogéneo no corresponde necesariamente a un grupo lingǘstico determinado. Por ejemplo, los pueblos indios del sur de México en alguna forma constituyen grupos con cierta homogeneidad entre ellos, aunque no hablen las mismas lenguas.

Para poder entender la dinámica cultura-pensamiento-lenguaje, debemos tratar de comprender cuáles son las características universales, comunes a todas las lenguas y cuáles las que son particulares a cada una. También debemos distinguir conforme lo que nos han enseñado en los últimos años las ciencias que relacionan el comportamiento social y cultural con el pensamiento y con la lengua, que hay ciertos 
modelos de pensamiento y de acción que son comunes a varios grupos lingüísticos y que, por lo tanto, sobrepasan la noción de lengua. En esto último, se ha estado investigando con gran rigor en los años recientes, en la llamada tipología lingüística, y es ésta una veta que se debe seguir analizando si queremos comprender la acción, el pensamiento lingǘstico, la cultura y el cambio.

En lo que respecta a considerar el lenguaje como acción, nos parece indispensable seguir el camino del análisis de las acciones que se realizan mediante el lenguaje. De hecho, si leemos los periódicos o analizamos la función de los medios masivos de comunicación, vemos que estamos en un mundo lleno de actos ilocutivos y que como resultado de ello las acciones perlocutivas de los lectores o de los televidentes, en el mejor de los casos, se dejan persuadir o convencer para creer o hacer algo, pero en gran parte de la ocasiones, también los actos de habla llevan al receptor a rebelarse contra actos perlocutivos que pretenden someter al oyente como si fuera un ente sin voluntad y sin raciocinio propios. Esto nos lleva a considerar que la acción, el pensamiento y la cultura, desde luego, también están íntimamente relacionados, por lo que no podemos estudiar las acciones y los cambios que se realizan por medio del lenguaje, sin tomar en cuenta cuáles son las formas lingǘsticas propias de esos actos en cada comunidad lingüística o en cada grupo social. Lenguaje, cultura, acción y cambio es una relación inseparable que nos permite comprender lo que es la sociedad; no así el análisis aislado, ya sea de elementos lingüísticos fuera de contexto, o de ideas entresacadas de la interacción social, o de aparentes leyes del pensamiento que se contraponen a la práctica de la lengua y sus acciones.

Por eso, nuestra tarea debe estar centrada en la relación de lengua, conducta, ideas, pensamientos, acciones, reacciones y cambios. Sólo teniendo en cuenta este amplio universo, podremos entender lo que es la capacidad del lenguaje humano.

\section{BIBLIOGRAFÍA}

Austin, John L. (1990). Cómohacercosasconpalabras Palabrasyaciones Ed. de J. O . Urmson. Trad. de G enaro R. Carrió y Eduardo A. Rabossi. Barcelona-Buenos Aires-México: Paidós. (Paidós Studio 22) [1ª̣ed. 1962].

Bloomfield, Leonard (1964). Lengraje Pról. y bibliografía complementaria de Alberto Escobar. Lima: Universidad Nacional Mayor de San Marcos. [1ª ed. inglesa, 1933].

Humboldt, Wilhelm von (1990). Sdbeladiversidaddela estructuradd lengrajehumamoysuinflueniasdred desarrdloespiritual dela humanidad Trad. y pról. de Ana A gud. Barcelona: Ministerio de Educación y Ciencia; Madrid: Anthropos. (Autores, TextosyTemas Lingüstica, 1)

Lyons, John (1971). Introduciónenlalingüística teérica Trad. de Ramon Cerdá. Barcelona: Editorial Teide. [1 ${ }^{\mathrm{a}}$ ed. 1968] 
- - (1980). Semántica Trad. de Ramon Cerdá. Barcelona: Editorial Teide. [1ª ed. 1977]

Robins, R. H. (1979). Pequena históiadalingüstica Coleçao coondenada por Carlos Eduardo Falcao Uchôa. Traduçao Luiz Martins Monteiro de Barros. Rio de Janeiro: Ministério da Educaçao e Cultura-Ao Livro Técnico.

Sapir, Edward (1954). El lenguaje Introducciónal esudiodd habla Trad. de Margit y Antonio Alatorre. México: Fondo de Cultura Económica. (Breviarios Fondbde Cultura Económica, 96) [1ª ed. 1921].

Saussure, Ferdinand de (1967). Curso delingǘstica general. Trad. pról. y notas de

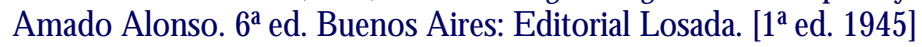

Searle, John R. (1994). Adtosdehabla. Ensayodefilosofíadd lenguaje Trad. de Luis M. Valdés Villanueva. 4a. ed. Madrid: Cátedra.

Vendler, Z. (1972). Rescogtans Ithaca, N.Y .-London: Cornell University Press.

Whorf, Benjamin Lee (1971). Lengraje pensamientoyrellidad Selección de escritos y pról. de Stuart Chase. Introd. de John B. Carroll. Trad. de José M. Pomares. Barcelona: Barral Editores. [1aed. 1956] 